\title{
Desenvolvimento de sistema para inspeção de elementos combustíveis de reatores nucleares de pesquisa Triga
}

\author{
Development of a system for fuel elements inspection of nuclear \\ research reactors Triga
}

\author{
Rogério Rivail Rodrigues \\ rrr@cdtn.br \\ Centro de \\ Desenvolvimento da \\ Tecnologia Nuclear/ \\ Comissão Nacional de \\ Energia Nuclear (CDTN/ \\ CNEN)
}

\section{Amir Zacarias Mesquita}

amir@cdtn.br

Centro de

Desenvolvimento da

Tecnologia Nuclear/

Comissão Nacional de

Energia Nuclear (CDTN/

CNEN)

\begin{abstract}
Resumo
O Centro de Desenvolvimento de Tecnologia Nuclear (CDTN) é um instituto de pesquisa administrado pela Comissão Nacional de Energia Nuclear (Cnen), localizada em Belo Horizonte. O CDTN é equipado com um reator nuclear Triga Mark I, que tem quase 60 anos de operação. A maioria dos seus elementos combustíveis se encontra no núcleo desde a primeira criticalidade e pode ocorrer corrosão, que ameaça a integridade dos revestimentos dos combustíveis. O refrigerante do reator deve ser tratado e controlado para manter sua baixa condutividade elétrica e $\mathrm{pH}$ próximo da neutralidade, a fim de minimizar a corrosão dos componentes do reator, principalmente dos elementos combustíveis. O objetivo deste trabalho é apresentar o sistema de monitoramento desenvolvido para a verificação de possíveis vazamentos nos elementos combustíveis Triga com base no teste de sipping. Uma correlação também foi desenvolvida para encontrar o diâmetro de um hipotético e pequeno orifício cilíndrico no revestimento do combustível em função dos valores da atividade do Cs-137 a serem medidos.

Palavras-chave: Reator nuclear de pesquisa. Triga. Sipping. Elemento combustível nuclear.
\end{abstract}

\begin{abstract}
The Nuclear Technology Development Center (CDTN) is a research institute administered by the Brazilian Nuclear Energy Commission (CNEN) located in Belo Horizonte/Brazil). The CDTN is equipped with a Triga Mark I nuclear reactor with almost 60 years of operation. Most of its fuel elements are in the core since the first criticality, and corrosion may occur that threaten the integrity of spent fuel claddings. The reactor coolant must be treated and controlled in order to maintain its low electrical conductivity and $\mathrm{pH}$ close to neutrality, in order to minimize the corrosion of the reactor components, mainly the fuel elements. The objective of this work is to present the leak monitoring system developed for the verification of possible leaks in the Triga fuel elements based on the sipping test. A correlation was also developed to find the diameter of a hypothetical small cylindrical hole in the fuel cladding as a function of Cs-137 activity values to be measured.
\end{abstract}

Keywords: Nuclear research reactor. Triga. Sipping. Nuclear fuel element.

\section{Introdução}

Os reatores nucleares de pesquisa Triga (Training, Reactor, Isotopeproduction, General Atomics), conforme indica seu acrônimo, foram desenvolvidos, principalmente, para formação de pessoal, produção de radioisótopos e pesquisa. Esses reatores estão, em sua maioria, instalados em universidades e centros tecnológicos. O reator de pesquisa Triga IPR-R1, mostrado na figura 1, foi adquirido pelo governo do estado de Minas Gerais em 1960, através do programa do governo americano "Átomos para a Paz". Foi instalado no antigo Instituto de Pesquisas Radioativas (IPR), atual Centro de Desenvolvimento da Tecnologia Nuclear (CDTN), localizado no campus da Universidade Federal de Minas Gerais (UFMG). A primeira criticalidade do IPR-R1 ocorreu em 06 de novembro de 1960, com uma potência térmica máxima de $30 \mathrm{~kW}$, e foi o segundo reator nuclear instalado no Brasil.

O Triga IPR-R1 é um reator do tipo poço, ou seja, encontra-se imerso em um tanque cilíndrico, cujas paredes são revestidas com alumínio, tendo 1,92 $\mathrm{m}$ de diâmetro e 6,62 $\mathrm{m}$ de profundidade. Esse volume contém o núcleo do reator 
e suas estruturas associadas, e está abastecido com, aproximadamente, 18.000 litros de água deionizada, a qual serve não só como refrigerante, mas também como moderador secundário de nêutrons e blindagem biológica (CDTN/CNEN, 2008). A figura 1 mostra fotos do núcleo e do poço do reator, em que se pode ver a radiação de Cherenkov quando este se encontra em operação.

Figura 1 - Reator nuclear Triga IPR-R1 a vista do núcleo e o poço com o reator em operação.
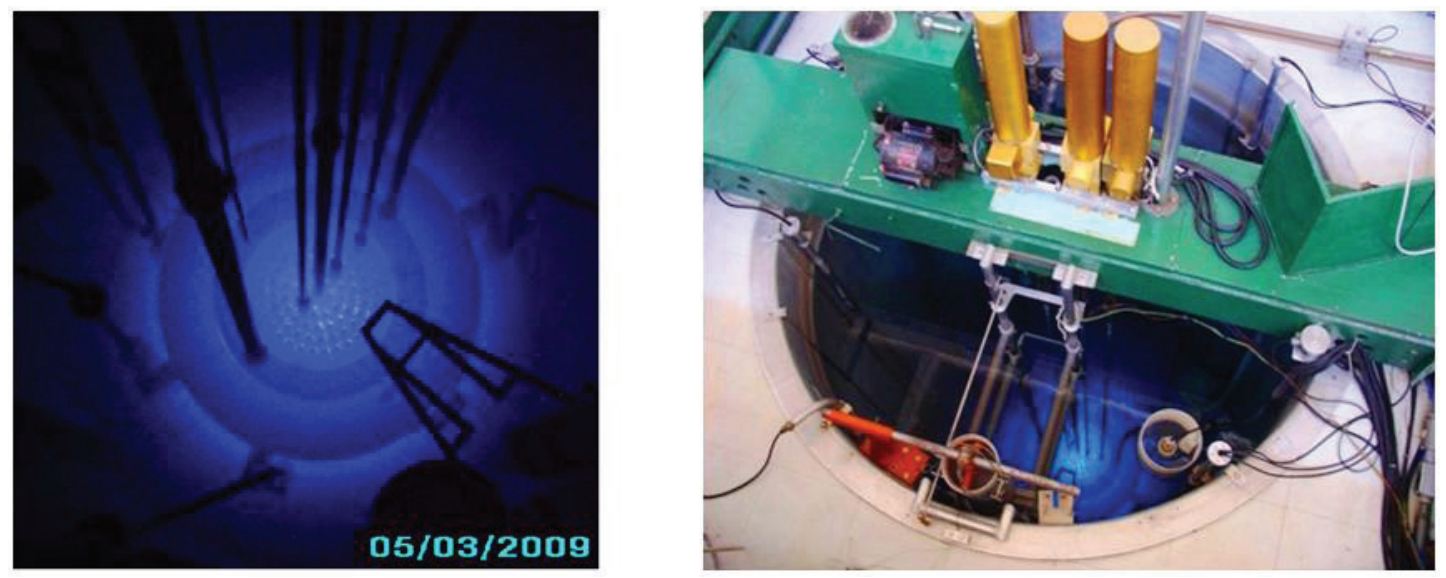

Fonte: Mesquita et al. (2012).

O núcleo do reator é constituído de elementos combustíveis de hidreto de urânio-zircônio, com $8 \%$ de urânio na liga, a qual apresenta um enriquecimento máximo em urânio de massa atômica $235\left({ }^{235} \mathrm{U}\right)$ de, aproximadamente, 20\% (SIMNAD, 1981). Sua carga inicial era composta de 59 elementos combustíveis encapsulados em alumínio tipo AL1100F. Com a finalidade de aumentar a potência do reator, foram adquiridos nove elementos combustíveis revestidos de aço inoxidável tipo AISI-304, em 1971. Em dezembro de 2000, quatro desses elementos combustíveis foram inseridos no núcleo, permitindo aumentar a potência nominal para $250 \mathrm{~kW}$ (MESQUITA, 2005). A figura 2 mostra um elemento combustível com revestimento em alumínio.

Figura 2 - Detalhes construtivos de um elemento combustível Triga revestido em alumínio.

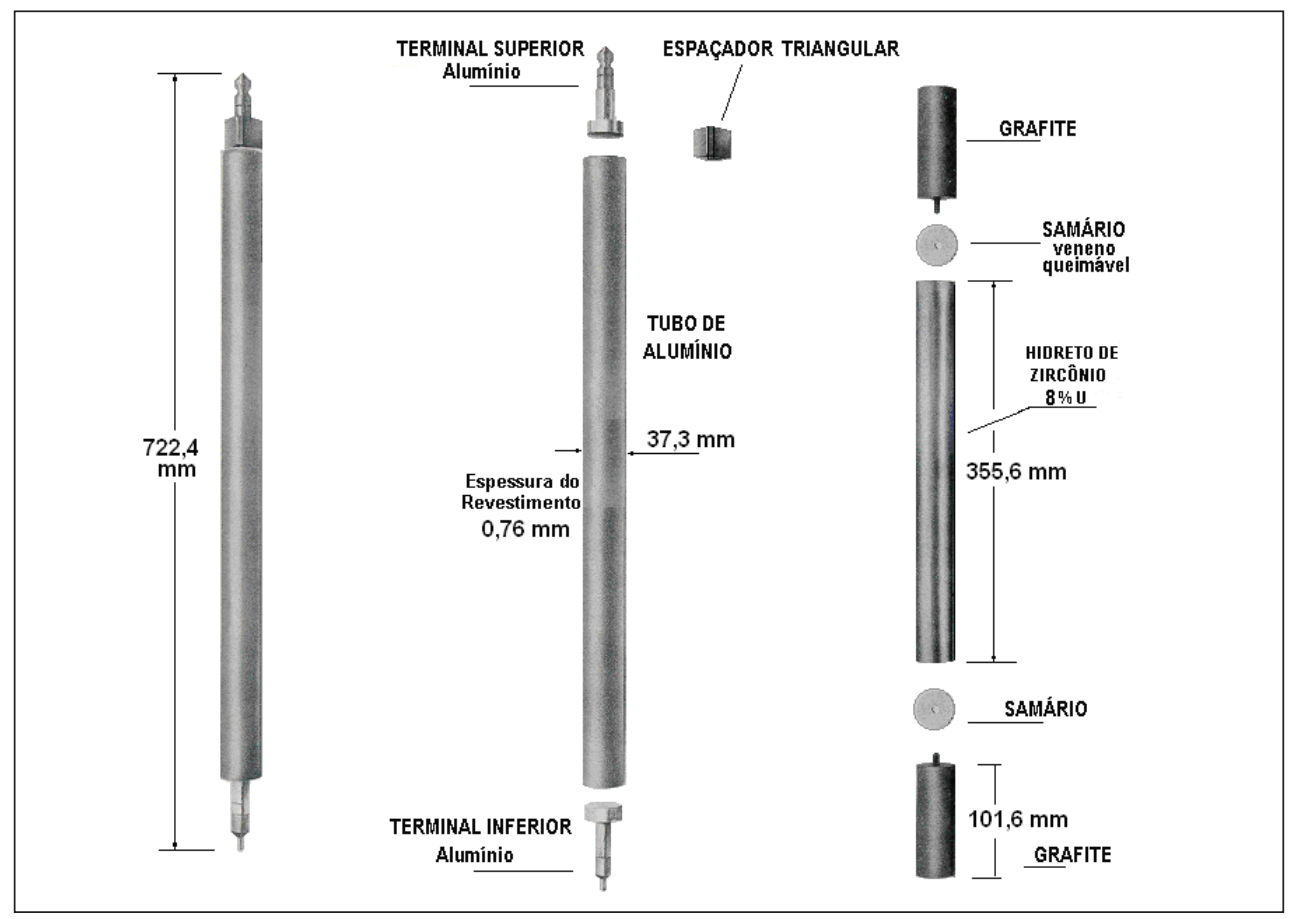

Fonte: CDTN/CNEN, (2008) 
Na figura 3 tem-se uma fotografia da parte superior do núcleo, tirada durante a inspeção visual realizada em 2006 (ALENCAR et al., 2006). Podem ser vistos na foto os terminais dos elementos combustíveis, os tubos guias das barras de controle e os tubos dos canais de irradiação. Os pontos brancos são ruídos no filme devido à radiação.

Figura 3 - Vista do topo do núcleo utilizando câmera submersa.

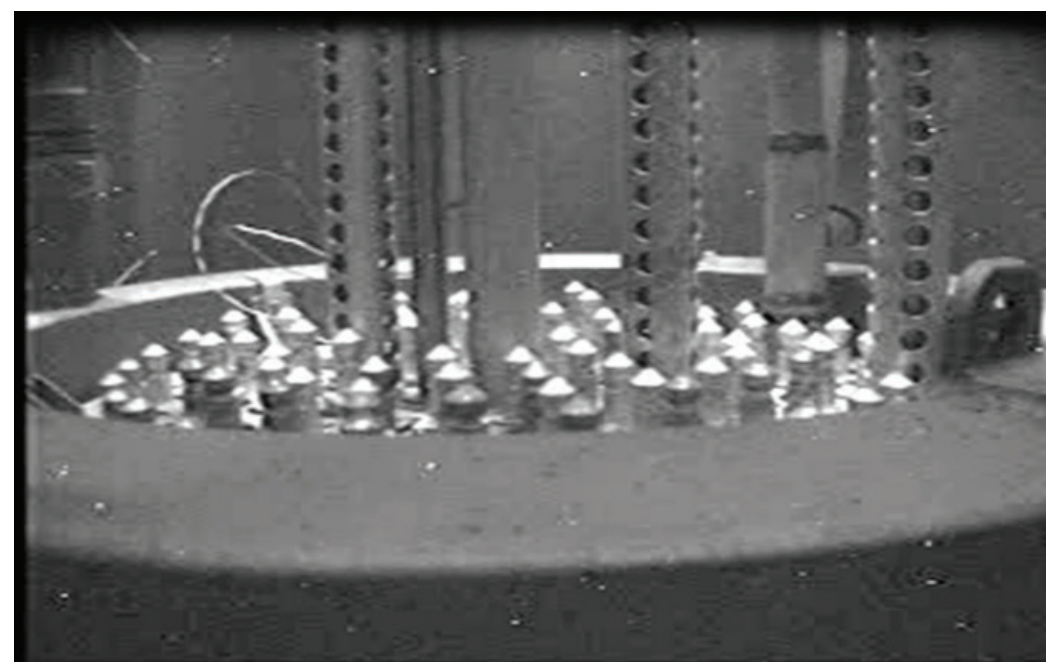

Fonte: Alencar et al.(2006).

No reator Triga IPR-R1, os 59 elementos originais, revestido em alumínio, têm a espessura da parede de 0,76 mm. Os quatro elementos em aço inoxidável, adicionados no ano 2000, têm espessura de parede de 0,50 mm (CDTN/CNEN, 2008). Estas espessuras de parede são projetadas para serem as menos espessas possíveis, de modo a melhorar a condução de calor e do fluxo de nêutrons, mas, por outro lado, tornam delicada a manipulação dos elementos combustíveis. Este reator tem quase 60 anos de operação e foi amplamente utilizado no treinamento de operadores de reatores. Nas aulas práticas, a manipulação dos elementos combustíveis ocorre, por exemplo, nas aulas de aproximação subcrítica, quando elementos combustíveis são retirados do núcleo e depois inseridos. A manipulação pode levar a danos no encapsulamento, como arranhões, furos, ou rasgos, devido à delicada espessura do revestimento de alumínio. O revestimento em aço inoxidável é mais resistente mecanicamente do que o revestimento em alumínio, devido às diferentes propriedades desses materiais (ASME, 2010; IAEA, 2003). Na inspeção visual realizada por Alencar et al. (2006) usando uma câmera submersa, pontos de corrosão foram observados em alguns elementos com revestimento em alumínio. Outros elementos combustíveis estavam com o pino inferior amassado, conforme mostra a figura 4.

Figura 4 - Elemento de combustível revestido de alumínio com pino de extremidade inferior amassado

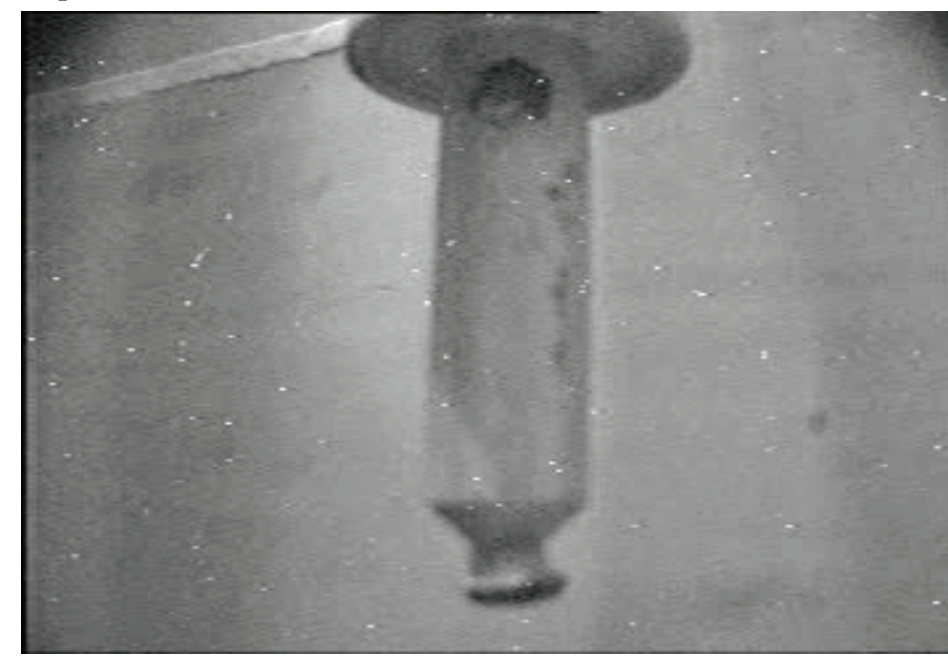

Fonte: Alencar et al.(2006) 
Com as modificações introduzidas no reator ao longo dos anos de operação, especialmente a inclusão no núcleo de elementos combustíveis revestidos de aço inoxidável, aumenta a probabilidade de ocorrência de corrosão. O principal motivo para a corrosão é a formação do par galvânico entre diferentes metais no mesmo corpo de dispersão de eletrólitos (GENTIL, 2011).

Embora a difusão de eletrólitos na água do poço seja mínima, como o poço do reator é aberto, sempre ocorre a incorporação de poeiras do ar na água do poço, causando a presença de materiais dissolvidos. Em poços de reatores nucleares de pesquisa, que são quase todos abertos ao ar, ocorre a possibilidade de inclusão de corpos estranhos variados, com possibilidade de acidente de interrupção de fluxo de refrigeração nos canais de convecção do núcleo (bloqueio de canal) inclusive. Este evento tem características diferentes dependendo da direção do fluxo do refrigerante. O fluxo para baixo pode levar ao bloqueio devido a objetos que caem no poço. O fluxo ascendente pode levar ao bloqueio devido a objetos dentro da tubulação do sistema de refrigeração primário, sendo arrastados para o núcleo pela ação da bomba (IAEA, 2015). Reis et al. (2015) realizaram uma avaliação teórica das consequências desse acidente para o reator Triga IPR-R1.

Gases oxidantes, como o próprio oxigênio dissolvido na água do poço, podem aumentar a concentração de íons dissolvidos no meio refrigerante do núcleo do reator. Existe um estudo realizado por Sabino (1999) que descreve que a maior parte do material flutuante na água do poço é constituída de micro-organismos. Entre esses organismos, podese citar o Tricodermasp. Encontrou-se também presente resíduos da própria resina de purificação da água na época do estudo. Foram tomadas medidas mitigadoras para evitar a presença de particulados da resina na água. Entretanto, a presença de micro-organismos permanece e, a despeito da conclusão dos autores daquele trabalho, de que a presença de material orgânico não afeta a condição de corrosão do meio, existe a possibilidade de acidificação da água por atividade microbiológica em função da consequente produção e liberação de ácidos orgânicos pelo micro-organismo Trichodermasp (CALAZANS, 2012; FREITAS, 2017). Esses ácidos orgânicos, embora tenham um alto coeficiente de dissociação ácida em água $(\mathrm{pKa})^{1}$ em geral, podem conduzir a ataques, especialmente a peças de alumínio e de aço inoxidável. Estes metais são, exatamente, os componentes das estruturas encontradas neste reator. Esta condição pode favorecer a formação de pilhas galvânicas, que podem levar à corrosão eletroquímica nas várias estruturas, incluindo o revestimento de alguns dos elementos combustíveis (GENTIL, 2011). A figura 5 mostra a presença de fungos depositados na parede interna do tanque do reator, os quais foram identificados na inspeção visual realizada em 2006 (ALENCAR et al., 2006; RODRIGUES; MESQUITA, 2013).

Figura 5 - Precipitados depositados na parede interna do tanque.

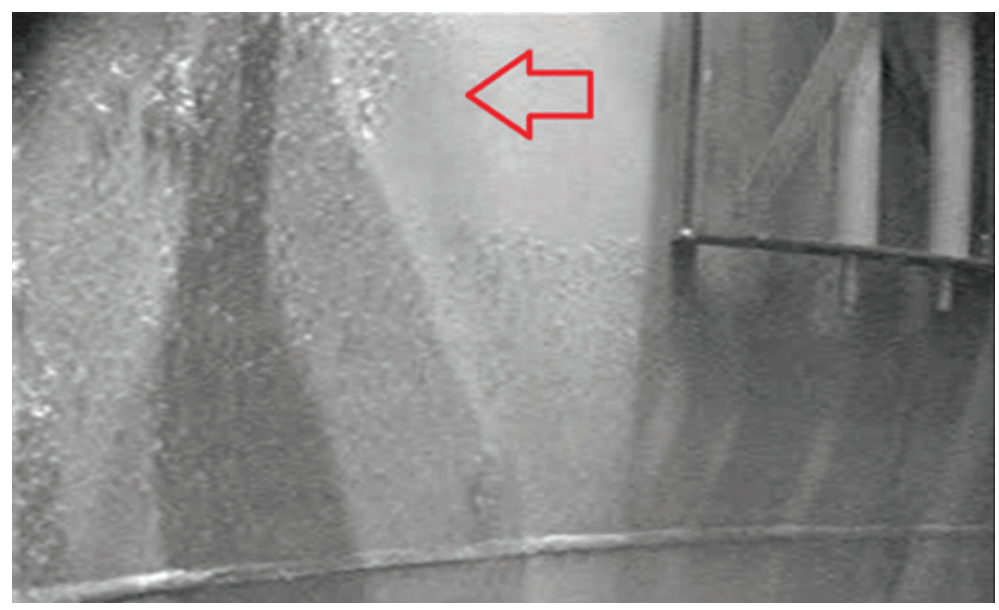

Fonte: Rodrigues e Mesquita (2013).

${ }_{\mathrm{p}} \mathrm{K}_{\mathrm{a}}$ é a grandeza que quantifica a força de um ácido. Representa a função $\mathrm{f}(\mathrm{Ka})=-\log \left(\mathrm{K}_{\mathrm{a}}\right)$, sendo Ka a razão de concentração entre reagentes e produtos da reação de dissociação de ácidos e bases em água. Um ácido fraco tem pKa alto, ou mais positivo, que um ácido forte. 
Foram feitas imagens durante as observações exploratórias de amostras de torta de filtro de água, recolhidas após limpeza manual do tanque do poço do reator. Uma amostra desse material foi colhida e colocada em lâminas de microscópio dissolvidas, parcialmente, em água destilada e deionizada. As imagens feitas a partir do sistema de microscopia ótica mostram elementos em suspenção. A fotografia da figura 6 mostra três regiões distintas com comportamentos peculiares. A região marcada com um círculo amarelo se comporta como um precipitado de microrganismos inativos. A região marcada com um círculo azul mostra partículas menores de aglomerados de microrganismos inativos soltos na corrente de água de dissolução. A região marcada em vermelho mostra partículas móveis de microrganismo que, aparentemente, manifestam movimento próprio, diferente do movimento comum causado pelo efeito browniano observado nas outras regiões marcadas. A região em vermelho, possivelmente, registra elementos biológicos com características de protozoários em processo de ressuscitação após contato com a água de dissolução. Estes resultados indicam que mais investigações devem ser conduzidas para que as espécies presentes na torta de filtrado de suspenções de lodo, presentes na água de refrigeração, sejam identificadas e estudadas do ponto de vista biológico.

Figura 6 - Material coletado no filtro do sistema de refrigeração com ampliação de 400x.

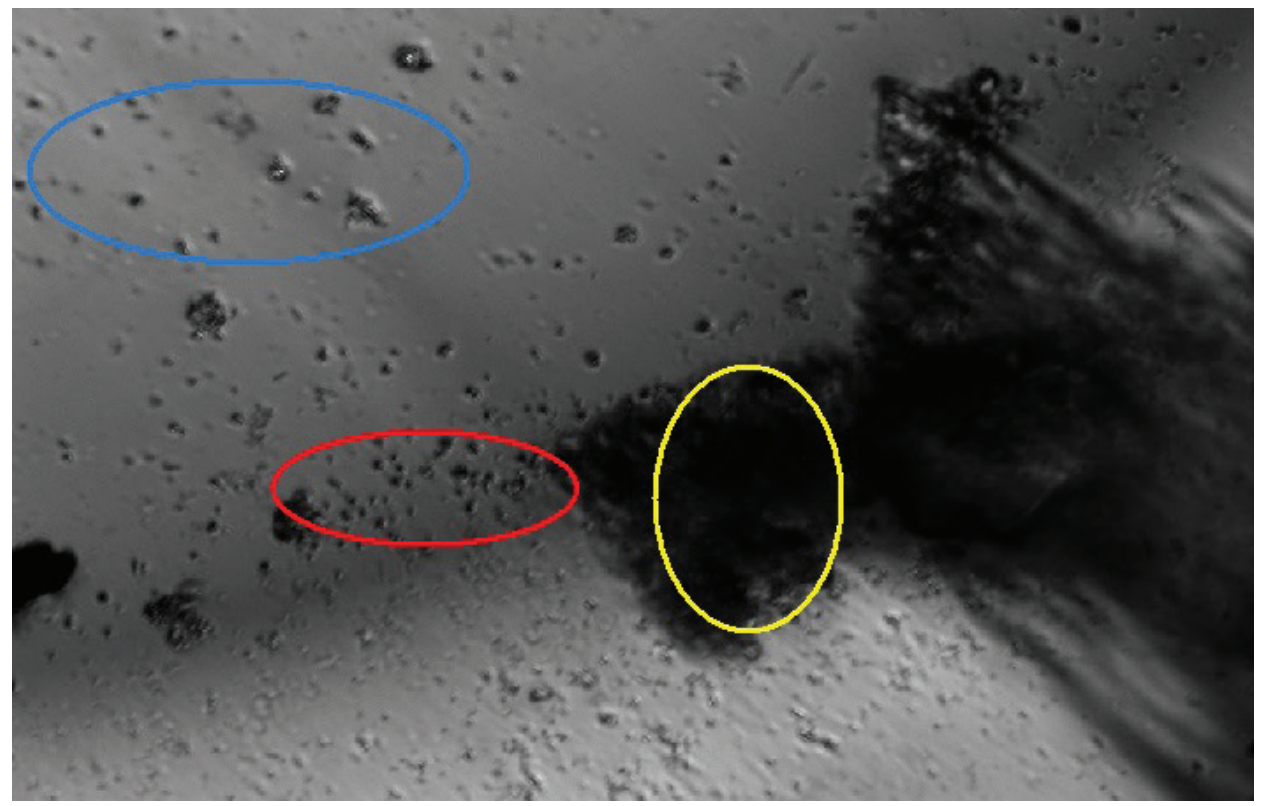

Fonte: Rodrigues e Mesquita (2013).

\section{Metodologia}

O teste de sipping é a técnica mais comum utilizada para localizar falhas de combustível, tanto em reatores à água pressurizada (PWR) como em reatores à água fervente (BWR). Sipping é um método não destrutivo usado para testar falhas nos elementos combustíveis, investigando os produtos de fissão liberados em um volume fixo do refrigerante. Os radioisótopos detectados incluem: criptônio, xenônio, césio, iodo, etc. Esse método, geralmente, é implementado como uma forma de monitorar a integridade dos elementos combustíveis em reatores nucleares de pesquisa, que podem ser afetados pela corrosão em longos períodos. O teste de sipping também pode ser empregado para investigar elementos combustíveis que são suspeitos de ter falhado durante o curso de operação (PARK et al., 2014).

O objetivo principal deste projeto é desenvolver um sistema para verificação de possíveis vazamentos em elementos combustíveis de reatores nucleares de pesquisa. A forma de verificação será construir e dispor um arranjo no poço do reator que possa receber um pequeno número de elementos combustíveis. Esse arranjo terá certa quantidade de água deionizada separada da do restante da água do poço. Depois de cerca de um determinado período, a água do recipiente deverá ser amostrada. Alíquotas da água de lixiviação contida no tanque do aparelho após o teste serão tomadas e enviadas para análise. As amostras devem ser analisadas por equipamento, que fará a detecção e identificação de produtos de fissão que vierem a ser liberados. 
Sendo constatada a presença dos isótopos Cs-137, La-140 e I-131, resta indicado que alguns dos elementos combustíveis amostrados apresentam vazamentos, ou seja, estão com o revestimento comprometido, uma vez que esses elementos são indicadores conhecidos de vazamentos em reatores nucleares. O sistema será adaptado e ficará disponível para analisar e identificar a presença de elementos químicos na água de refrigeração do núcleo em testes periódicos.

\section{Resultados e discussão}

Os resultados serão apresentados em dois tópicos considerando-se os objetivos traçados na pesquisa.

\subsection{Dispositivo para o teste de sipping desenvolvido}

Um dispositivo para o teste de sipping foi projetado e construído para receber no máximo três elementos combustíveis de cada vez. O manuseio dos elementos será realizado através de uma ferramenta conhecida como "pinça articulada para manusear dispositivos e equipamentos à distância". Este equipamento foi patenteado pelo CDTN/CNEN (2011) (Figura 7). A ferramenta será manuseada pelos operadores licenciados do reator. Mesmo com todos os cuidados relativos à operação, existe o risco de ocasionar fricção do revestimento com as estruturas metálicas do núcleo.

Figura 7 - Pinça articulada para manuseio dos elementos de combustíveis.

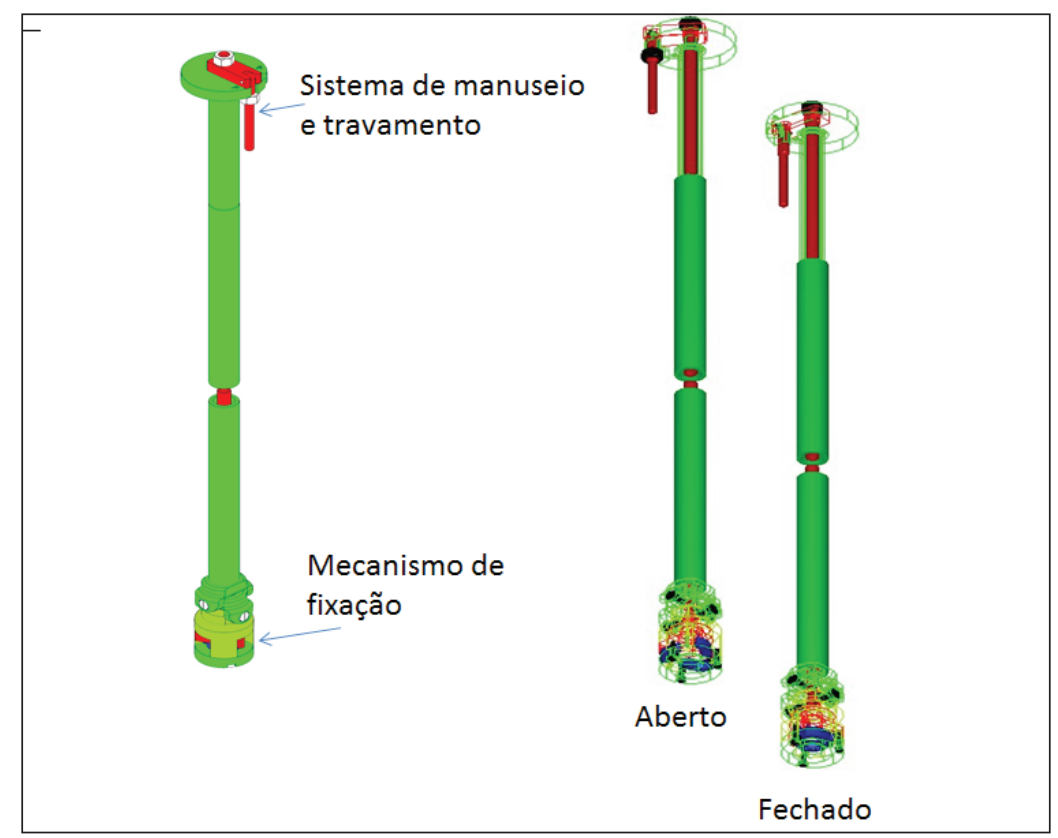

Fonte: Adaptado de CDTN/CNEN (2011).

O dispositivo para o teste de sipping é composto por um recipiente para acomodar 40 litros de água e um cesto para inserir os elementos combustíveis (Fig. 8). A água será tomada da própria água do poço do reator. Uma amostra inicial será retirada como amostra de branco e outra amostra, ao final da batelada teste, será retirada como amostra de análise, sendo o resultado do branco descontado do resultado da amostra de análise. Dentro do recipiente é inserido o cesto com capacidade para colocar até três elementos combustíveis por teste. A cesta pode ser colocada fora da piscina, ou ao lado do núcleo do reator, para que o operador possa transportar os elementos combustíveis do núcleo para a cesta e vice-versa.

O recipiente ficará fixado, durante o teste, em um apoio na borda do poço projetado para sustentar todo o sistema. O recipiente tem um furo no seu topo que transborda o excesso de água, garantindo sempre o mesmo nível de água em seu interior. Este recipiente não terá mais comunicação com a água do poço do reator, sua água ficará isolada do restante da água do reator. Não é necessário o emprego de água pura para encher o recipiente durante o teste. A água do próprio poço servirá, por que representa um volume muito menor que a carga total de água do poço, em uma razão de 40 1/18 000 1. O objetivo de reduzir o volume de água é concentrar a possível ocorrência dos produtos de fissão, de forma a torná-lo perceptível no sistema de espectrometria gama que será empregado para análise. 
Após cerca de 16 horas de manutenção dos elementos combustíveis no recipiente do dispositivo, sua água será amostrada. Alíquotas da água de lixiviação serão tomadas para análise. As amostras de água serão analisadas pelo método de espectrometria gama, utilizando HPGe (High Pure Germanium Spectrometer Multichannel Analyzer).

Figura 8 - Esquema simplificado do dispositivo de sipping:

a) recipiente e cesto; b) cesto dentro do recipiente.

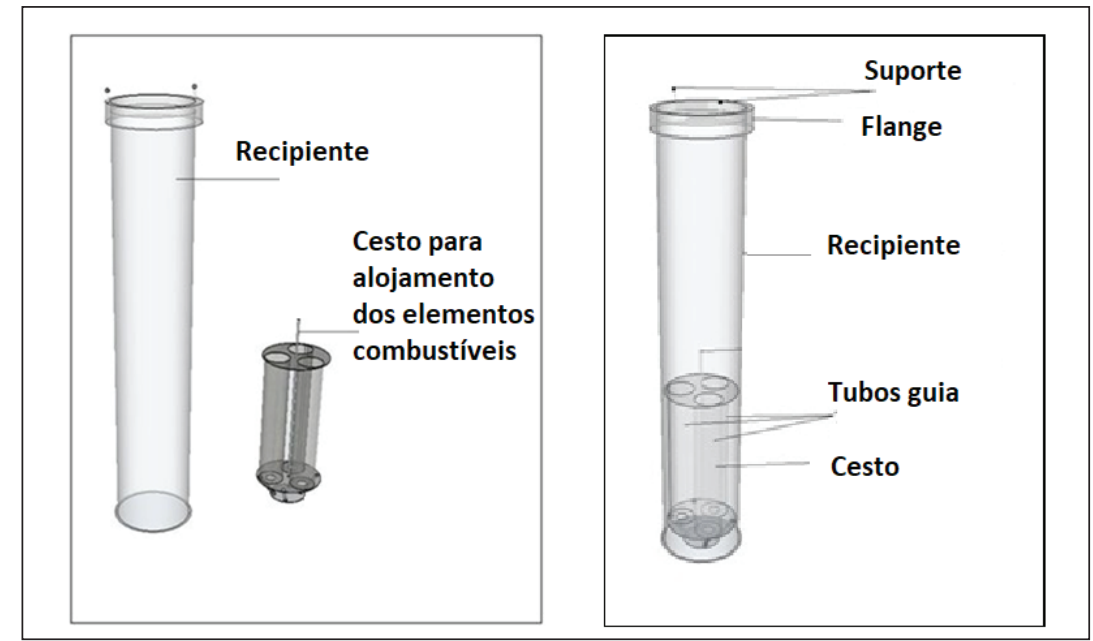

Fonte: Elaborado pelos autores.

As fotografias da figura 9 mostram detalhes do aparelho construído para realizar o teste. A fotografia da figura 9a mostra o recipiente em que o cesto com os elementos combustíveis será inserido. A foto da figura $9 \mathrm{~b}$ mostra a cesta com três elementos combustíveis. A figura $9 \mathrm{c}$ e figura $9 \mathrm{~d}$ mostram detalhes dos terminais superior e inferior dos elementos combustíveis.

Figura 9 - Detalhes do aparelho para o teste de sipping desenvolvido.

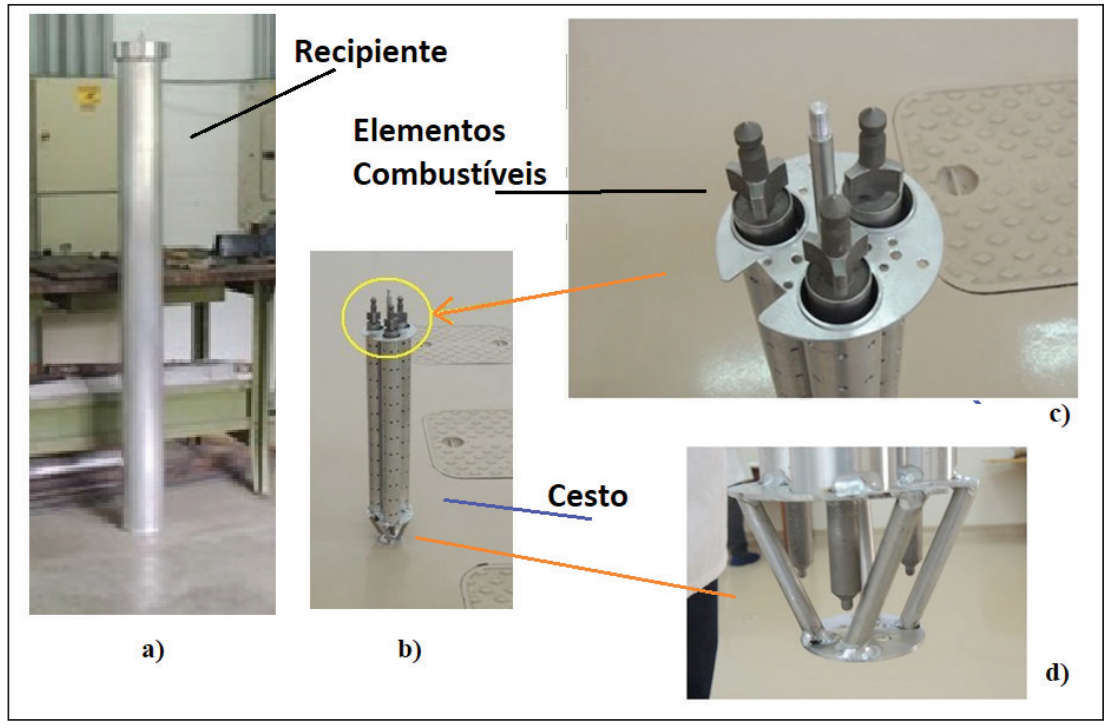

Fonte: Elaborado pelos autores.

O esquema da figura 10 mostra o recipiente do sistema de sipping no fundo da piscina do reator, pronto para receber elementos combustíveis para o teste. 
Figura 10 - Recipiente do dispositivo de sipping no fundo da piscina do reator.

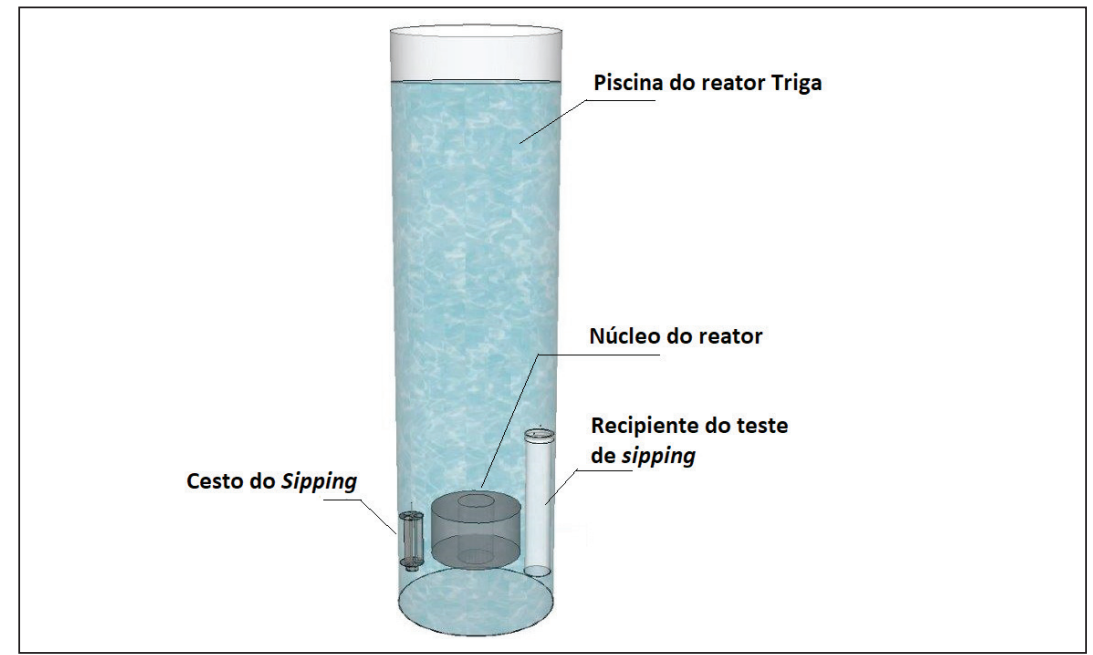

Fonte: Elaborado pelos autores.

A figura 11 mostra o posicionamento do recipiente na borda da piscina do reator carregado com três elementos combustíveis a serem submetidos ao teste de sipping.

Figura 11 - Posicionamento do recipiente na borda da piscina carregado com três elementos combustíveis.

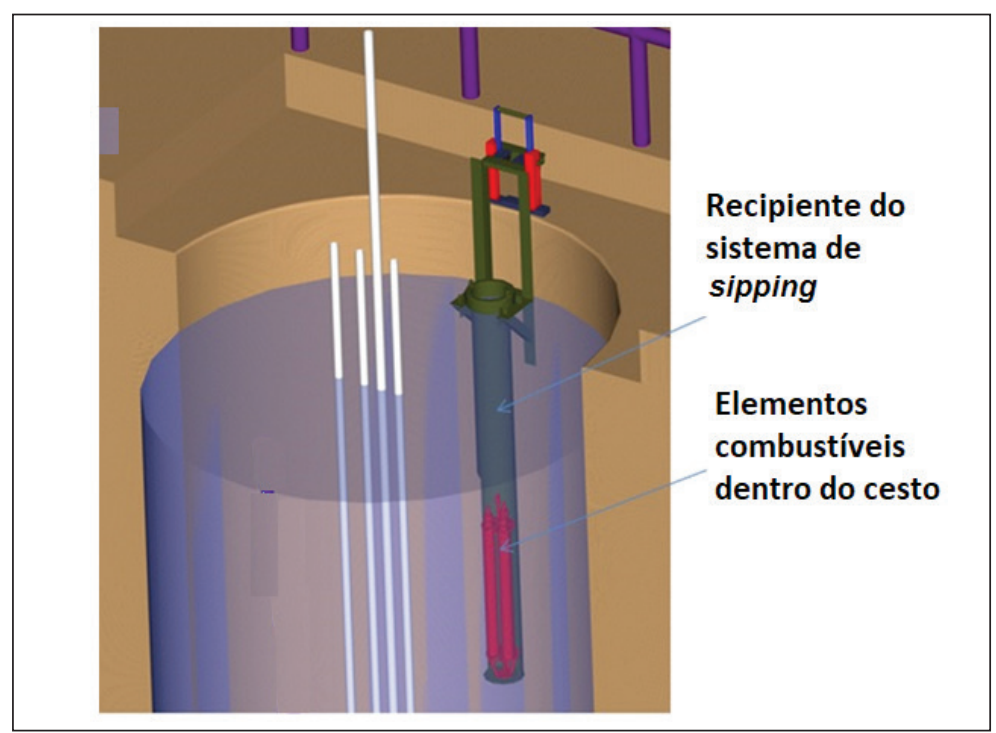

Fonte: Elaborado pelos autores.

\subsection{Modelo de difusão do Cs-137 na água do recipiente de sipping}

Para realizar o teste de sipping em elementos combustíveis irradiados, armazenados por muitos anos na piscina do reator, o produto de fissão mais adequado para monitoramento de falha é o césio-137, devido à sua longa meia-vida (30,14 anos), bom rendimento em relação aos outros produtos de fissão e alta solubilidade em água (PERROTA et al., 1998; TERREMOTO et al., 2008). Assim, foi desenvolvida uma correlação para encontrar o diâmetro de um hipotético e pequeno orifício cilíndrico no revestimento do combustível em função da atividade Cs-137.

A difusão do césio em um meio material pode ser descrita pela lei de Fick, que prescreve que a densidade do fluxo de difusão de uma substância é linearmente proporcional ao seu gradiente de concentração. No caso descrito aqui, o meio é a água da piscina do reator Triga. Então, a difusão de um produto de fissão (Cs-137) é descrita pela seguinte equação diferencial parcial: 


$$
f=-D \nabla . c
$$

Onde $f$ é uma grandeza vetorial que representa a densidade de fluxo da atividade do césio $\left(\mathrm{Bq} \cdot \mathrm{m}^{2} \cdot \mathrm{h}^{-1}\right), D$ é o coeficiente de difusão e $\nabla c$ representa o gradiente de concentração da atividade do césio na água. Portanto, o coeficiente de difusão $D$ pode ser definido a partir da equação de Fick e expresso como:

$$
D=f / \nabla \cdot c
$$

A difusão de um produto de fissão radioativo através de um dado meio é descrita por meio da seguinte equação diferencial parcial (FRISKNEY; SPEIGHT, 1976):

$$
D . \nabla^{2} \rho-\lambda . \rho+S=\frac{\partial \rho}{\partial t}
$$

Onde: $\rho$ é a concentração de átomos ou íons do produto de fissão no meio (átomos $/ \mathrm{cm}^{3}$ ), $D$ é o coeficiente de difusão do produto de fissão no meio $\left(\mathrm{cm}^{2} / \mathrm{s}\right), \lambda$ é a constante de decaimento radioativo do produto de fissão (1/s) e $S$ é o termo fonte que descreve a taxa de produtos de fissão gerados no meio (átomos $/ \mathrm{cm}^{3}$ ).

Após várias operações algébricas, foi encontrado o raio médio de um hipotético e pequeno orifício cilíndrico (Fig. 12) no revestimento do combustível em função da atividade de Cs-137, mostrado na equação 4 :

$$
r_{0}=\frac{-1}{\left(\pi \cdot\left(f \cdot\left(\lambda \cdot\left(S_{0}\left(a^{2}+6 \cdot D \cdot t\right)\right)\right)\right)\right)} \cdot \frac{a \cdot V o l \cdot \sqrt{3}}{\sqrt{a \cdot V o l}} \sqrt{2} \cdot \pi \cdot f \cdot \lambda \cdot S_{0} \cdot\left(a^{2} \cdot+6 \cdot D\right) \cdot A(t)
$$

Onde:

$r_{0}=$ raio médio do furo cilíndrico equivalente no revestimento;

$S_{0}$ é a concentração inicial de átomos do produto de fissão no elemento combustível (átomos $/ \mathrm{cm}^{3}$ ), medida no momento em que a falha atinge o combustível, ou seja, quando $\mathrm{t}=0$;

$\mathrm{Vol}=$ volume de água contida no recipiente do aparelho de sipping;

$A(t)=$ atividade no tempo $t$;

$f=$ fração da concentração de Cs-137 presente no combustível irradiado que é limitado pela água de lixiviação no recipiente de sipping;

$\lambda=$ constante de decaimento do Cs-137;

$a=$ comprimento total do furo (profundidade);

$D=$ coeficiente de difusão de Cs-137 na água de lixiviação;

$t=$ duração do teste de sipping.

Figura 12 - Desenho esquemático que mostra o comportamento da difusão do Cs-137 na hipótese de uma concentração média ao atingir o equilíbrio após um longo período de tempo.

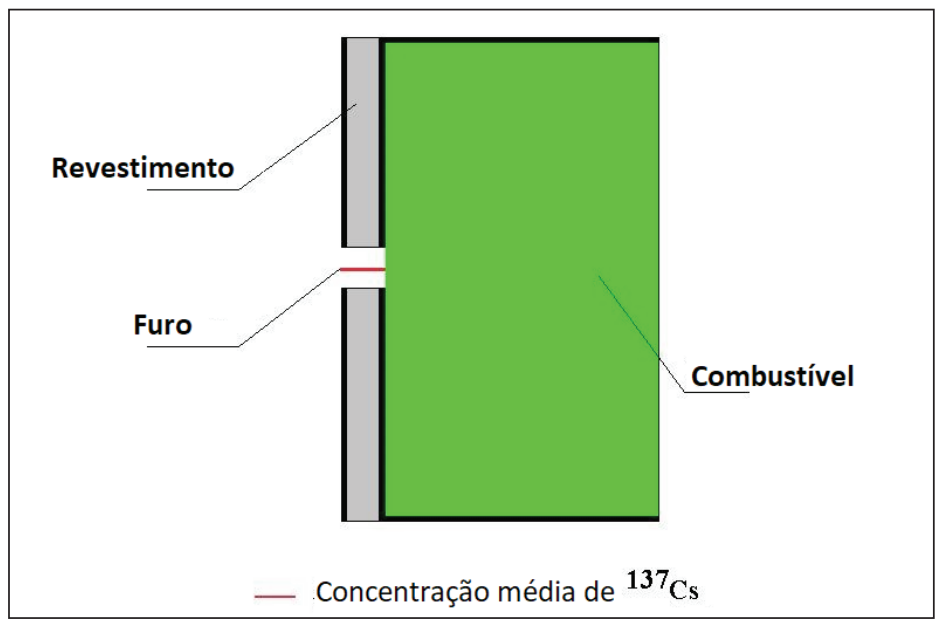

Fonte: Elaborado pelos autores. 


\title{
4 Conclusão
}

O teste de sipping é uma técnica não destrutiva empregada para avaliar a integridade estrutural do revestimento dos combustíveis nucleares irradiados que se baseia na detecção de vazamentos de produtos de fissão radioativos no refrigerante do reator por meio de espectroscopia de raios gama. Um sistema de sipping foi desenvolvido para avaliar a integridade dos elementos combustíveis em uso no reator Triga IPR-R1. É necessário manter os produtos de fissão dentro dos elementos combustíveis e evitar sua fuga para o meio ambiente. No reator de pesquisa Triga IPR-R1, os elementos combustíveis estão em operação há décadas e pode ocorrer corrosão, levando a falhas.

O IPR-R1 foi um dos primeiros reatores do tipo Triga a entrarem em operação no mundo. Ele tem sido amplamente utilizado no treinamento de operadores de reatores, o que inclui aulas práticas com manipulação dos elementos combustíveis. A manipulação causa fricção no revestimento e pode causar danos. Na inspeção visual realizada em 2006, verificou-se a presença de pits no revestimento de alguns elementos combustíveis. Com a inclusão no núcleo de alguns elementos combustíveis revestidos de aço inoxidável, atuando juntamente com os elementos combustíveis revestidos em alumínio, aumenta a possibilidade de corrosão devido ao par galvânico formado.

No reator Triga IPR-R1, apesar de seus quase 60 anos de operação, nunca foi realizado um teste de sipping. Assim, foi construído um sistema para realizar esse teste de acordo com a metodologia descrita aqui. O sistema está pronto para executar o teste. Uma correlação entre a atividade de uma possível liberação de césio-137 na água e o diâmetro de um furo hipotético também foi desenvolvida. $\mathrm{O}$ resultado desse teste dará subsídios para a tomada de decisão quanto à necessidade de recuperar ou substituir o elemento de combustível falhado.

O Brasil tem quatro reatores nucleares de pesquisa em operação: o MB-01, uma instalação crítica de $0,1 \mathrm{~kW}$; o IEA-R1, um reator tipo piscina de $5 \mathrm{MW}$; o Argonauta, um reator do tipo Argonaut de $500 \mathrm{~W}$; e o IPR-R1, um reator tipo Triga Mark I de $250 \mathrm{~kW}$. Três desses reatores operam há mais de 46 anos, o que significa que ultrapassaram a faixa de expectativa de vida de 40 anos, recomendado para os reatores de pesquisa. A metodologia descrita aqui, com algumas adaptações, pode ser usada para testar os elementos combustíveis desses reatores. No futuro, também poderá ser usado no reator multipropósito brasileiro (RMB), atualmente em fase de projeto. A incorporação de procedimentos para a inspeção de rotina dos combustíveis aumentará sua vida útil, com confiabilidade e segurança nas operações.

\section{Agradecimentos}

Este projeto de pesquisa é apoiado pelas seguintes instituições: Centro de Desenvolvimento da Tecnologia Nuclear (CDTN), Comissão Nacional de Energia Nuclear (CNEN), Fundação de Amparo à Pesquisa do Estado de Minas Gerais (Fapemig) e Conselho Nacional de Desenvolvimento Científico e Tecnológico (CNPq).

\section{Referências}

ALENCAR, D. A. et al. Using visual inspection ndt to check integrity of Triga mark I fuel rods.In: 3nd. WORLD TRIGA USERS CONFERENCE, 3. Anais... Belo Horizonte, p. 1-6, 2006.

CALAZANS, P. N. Produção de aroma de coco por Trichoderma harzianum utilizando bagaço de cana. 2012. 108 f. Dissertação (Mestrado em Engenharia Química) - Universidade Federal do Sergipe, São Cristovão, 2012.

CENTRO DE DESENVOLVIMENTO DA TECNOLOGIA NUCLEAR, COMISSÃO NACIONAL DE ENERGIA NUCLEAR. Relatório de análise de segurança do reator Triga IPR-R1. Belo Horizonte: CDTN/CNEN, 2008.

\author{
CENTRO DE DESENVOLVIMENTO DA TECNOLOGIA NUCLEAR, COMISSÃO NACIONAL DE ENERGIA \\ NUCLEAR. Pinça articulada para manusear dispositivos e equipamentos a distância. Patente INPI No.: PI \\ 0803376-5 A2. Classificação: B25B 9/04, 11 out. 2011.
}

FREITAS, M. M. Aspectos gerais e morfológicos detrichoderma sp. Disponível em: <http://fitopatologia1.blogspot. com.br/2010/12/descricao-micologicaaspectos-gerais-e.html>. Acesso: 25 jan. 2017.

FRISKNEY, C.A.; SPEIGHT, M. V.A calculation on the in-pile diffusional release of fission products forming a general decay chain, Journal of Nuclear Materials, Berlim, v. 62, n. 1, p. 89-94, 1976. Disponível em: <DOI:10.1016/00223115(76)90286-5>. Acesso em: 25 jan. 2017. 
GENTIL, V. Corrosão. 6.a ed. Rio de Janeiro. LTC, - Livros Técnicos e Científicos Editora S.A. 2011.

IAEA - INTERNATIONAL ATOMIC ENERGY AGENCY. Corrosion of research reactor aluminium clad spent fuel in water. Vienna: IAEA, 2013. (Technical Reports Series, n. 418)

IAEA - INTERNATIONAL ATOMIC ENERGY AGENCY. Operating experience from events reported to theIAEA incident reporting system for research reactors. Vienna: IAEA-Tecdoc-1762, 2015.

MESQUITA, A. Z. et al. Experimental investigation of thermalhydraulics in the IPR-R1 Triga nuclear reactor. In: Amir Z. Mesquita; Iva Simcic. (Org.). Nuclear Reactors, Croácia. v. 1, p. 1-24. 2012. Disponível em: <DOI: 10.5772/25869>. Acesso em: 25 jan. 2017

MESQUITA, A.Z. Investigação experimental da distribuição de temperaturas no reator nuclear de pesquisa Triga IPR-R1. 2005. 179 f. Tese (Doutorado em Engenharia Química) - Universidade Estadual de Campinas Unicamp, São Paulo, 2005.

PARK, J. Y.; SHIM, M. S.; LEE, J. H. Current status of integrity assessment by sipping system of spent fuel bundles irradiated in Candu reactor. Nuclear Engineering and Technology, Berlim. v. 46, n. 6, p. 875-882, dec. 2014.

Disponível em: <DOI: 10.5516/NET.09.2014.018>. Acesso em: 30 jan. 2017

PERROTA, J. A.; TERREMOTO; L. A. A.; ZEITUNI, C. A. Experience on wet storage spent fuel sipping at IEA-R1 Brazilian research reactor. Annals of Nuclear Energy, Berlim. v. 25, n. 4-5, p. 237-258, 1998. Disponível em: <DOI: 10.1016/S0306-4549(97)00039-X>. Acesso em: 30 jan. 2017

REIS, P. A. L. et al. Simulation of a Trigareactor core blockage using Relap5 code. Science and Technology of Nuclear Installations. Nova York, v. 2015, ID do artigo 354163, p. 1-10, 2015. Disponível em: $<$ DOI: 10.1155/2015/354163>. Acesso em: 13 jan. 2017.

RODRIGUES, R. R.; MESQUITA, A. Z. Design of a system for fuel elements cladding inspection of a nuclear research reactor. In: INTERNATIONAL CONFERENCE ON INTEGRITY, RELIABILITY AND FAILURE (IRF’2013), 4. Anais.... Funchal, Ilha da Madeira. 2013. p. 69-70.

SABINO, C.V. Controle químico da água de refrigeração do reator Triga IPR-R1. Belo Horizonte, 1999. (Nota Técnica. CDTN/Cnen).

SIMNAD, M. T. The UZrHx alloy: its properties and use in Triga fuel. Nuclear Engineering and Design, Berlim, v. 64, n. 3, p. 403-422, abr. 1981. Disponível em: <DOI: 10.1016/0029-5493(81)90135-7>. Acesso em: 10 jan. 2017

TERREMOTO, L. A. A. et al. A model for release of fission products from a breached fuel plate under wet storage. Progress in Nuclear Energy, Berlim v. 50, n. 7, p. 818-827, set. 2008. Disponível em: <DOI: 10.1016/j. pnucene.2007.08.003>. Acesso em: 11 jan. 2017.

THE AMERICAN SOCIETY OF MECHANICAL ENGINEERS. ASME boiler and pressure vessel code - Materials - ASME Section II Part D - Properties (Customary) Materials. New York: ASME, 2010.

Sobre os autores

\section{Amir Zacarias Mesquita}

Engenheiro Eletricista, Universidade Federal de Minas Gerais - UFMG. Mestre em Ciências e Tecnologia Nuclear, Universidade Federal de Minas Gerais - UFMG. Doutor em Engenharia Química, Universidade Estadual de Campinas - UNICAMP. Pesquisador Titular III do Centro de Desenvolvimento da Tecnologia Nuclear da Comissão Nacional de Energia Nuclear - CDTN/CNEN. Docente Permanente do Programa de Pós-Graduação em Ciência e Tecnologia das Radiações, Minerais e Materiais do CDTN.

\section{Rogério Rivail Rodrigues}

Engenheiro Químico, Universidade Federal de Minas Gerais - UFMG, Mestre em Ciências e Tecnologia Nuclear, Universidade Federal de Minas Gerais - UFMG, Doutorado em andamento no Programa de Pós-Graduação em Ciência e Tecnologia das Radiações, Minerais e Materiais do CDTN. Tecnologista Pleno Centro de Desenvolvimento da Tecnologia Nuclear da Comissão Nacional de Energia Nuclear - CDTN/CNEN. 